\title{
COMPOSIÇÃO E PROPRIEDADES DA SEMENTE DE ABÓBORA
}

\section{COMPOSITION AND PROPERTIES OF PUMPKIN SEED}

\author{
Camilla Pereira do Vale ${ }^{1}$, Fernanda Cristina Cavalcante Loquete ${ }^{2}$, Morgana Gris \\ Zago $^{3}$, Pietra Vilani Chiella ${ }^{3}$, Daniela Miotto Bernardi ${ }^{*}$
}

\begin{abstract}
1 Tecnóloga em Gestão de Recursos Humanos, Nutricionista, Centro Universitário Fundação Assis Gurgacz - FAG. ${ }^{2}$ Tecnóloga em Alimentos. Acadêmica de Nutrição do Centro Universitário Fundação Assis Gurgacz - FAG. ${ }^{3}$ Nutricionista, Centro Universitário Fundação Assis Gurgacz - FAG. ${ }^{4}$ Nutricionista, doutora em Alimentos e Nutrição. Docentede Nutrição no Centro Universitário Fundação Assis Gurgacz - FAG

* Autor correspondente: danimiottober@gmail.com , https://orcid.org/0000-0001-9019-3835
\end{abstract}

\section{RESUMO}

Introdução: a semente de abóbora é considerada um subproduto e por muitas vezes é descartada, porém, vem ganhando importância devido a sua rica composição nutricional, além de efeitos anticancerígenos, antihelmínticos, antivirais, antiinflamatórios e antioxidantes. Ademais, é rica em ácidos graxos poliinsaturados, os quais são essenciais para o organismo, e em compostos bioativos, como carotenóides, vitaminas do complexo B, vitamina E e compostos fenólicos (principalmente fitoestrógenos). É também uma excelente fonte de fibras, que auxilia no trânsito intestinal e no aporte de ingestão diária. Carboidratos e proteínas também estão presentes na semente e podem auxiliar no aporte calórico. Objetivo: correlacionar diversos artigos já existentes sobre este vegetal e pontuar os principais nutrientes e propriedades funcionais presentes na semente de abóbora. Metodologia: trata-se de uma revisão de literatura de artigos e teses, publicados entre 1996 e 2019, que abordaram assuntos relacionados à semente de abóbora.

\begin{abstract}
Introduction: The pumpkin seed is considered a by-product and is often discarded, however, has been winning importance due to high nutritional value, as well as anticancer, anthelmintic, antiviral, anti-inflammatory and antioxidants effects. Moreover, it is rich in polyunsaturated fatty acids, which are essential for the organism, and in bioactive compounds, such as carotenoids, complex $B$ vitamins, vitamin $E$ and phenolic compounds (mainly phytoestrogens). The pumpkin seed is a excellent source of fibers, which assists in intestinal transit and contribution of daily intake. Carbohydrates and proteins are also present in the seed and can assist/contribution for the caloric intake. Objective: It is correlate several existing articles about this vegetable and to quote the main nutrients and functional properties present in the pumpkin seed. Methodology: It is a literature review of articles and theses, published between 1996 and 2019, which approach issues important related to pumpkin seed.
\end{abstract}

\section{INTRODUÇÃO}

A abóbora é um fruto da família das cucurbitáceas, rica em polissacarídeos, vitaminas, sais minerais, pectina e carbonato. Possui benefícios à saúde, como efeitos anticarcinogêncio, baixo índice glicêmico e baixo teor de lipídeos. Além disso, ela é capaz de remover inúmeros radicais livres gerados no 
próprio organismo durante o metabolismo, podendo ser anticoagulante, antioxidante, antiviral, dentre outras atividades biológicas (CHEN, L. 2018).

O cultivo desse vegetal é predominante na região do Nordeste brasileiro, pelo fato da diversidade genética da família cucurbitaceae presente nessa região. Dentre as espécies mais cultivadas estão à abóbora (Cucurbita moschata), a moranga (Cucurbita máxima) e o mogango (Cucurbita pepo)(SOUZA et al., 2012).

Economicamente, as espécies de abóboras, são de suma importância no mundo todo, pois estão entre os dez vegetais mais cultivados, principalmente em regiões temperadas e subtropicais (PARIS 1996;TADMORet al., 2005). A cucúrbita pepo, em especial, é considerada uma das espécies mais polimórficas em relação as suas características físicas, como cor, tamanho e formato (PARISet al., 2003;SAAVEDRA et al., 2013).

As partes de vegetais como folhas, cascas, sementes e talos, na maioria das vezes são descartados, pela indústria e pelos consumidores. Porém, esses subprodutos possuem alto teor de fibras e minerais, podendo ser utilizados na alimentação humana, visando agregar maior valor nutricional ao alimento (ROCHA, 2008).

Os frutos da abóbora são utilizados na alimentação humana, de forma direta e indireta, em especial pelas populações carentes do centro-sul e nordeste brasileiro, utilizados também em ração animal, e em suplementação de sopas e doces produzidos especialmente para recém-nascidos, sendo considerados uma excelente fonte de nutrientes (SILVA, 2006).

Na produção comercial de frutos de abóbora, destaca-se a semente como um subproduto do processamento, de alta qualidade, sendo utilizada como fator fundamental, devido as suas propriedades e a sua alta qualidade, por serem ricas em vitamina $A$, vitaminas do complexo $B$, cálcio, ferro, potássio, fósforo, silício, magnésio e sódio, com poucas calorias e de fácil digestão (SILVA, 2006; CARVALHO et al., 2009)

Um de seus antioxidantes mais abundantes são os carotenoides, compostos lipossolúveis que são responsáveis pela cor alaranjada, característica dessa espécie. O fato de maior relevância acerca desse composto é sua capacidade de redução de estresse oxidativo do organismo (SOUZA et al., 2012).Os carotenoides presentes na semente de abóbora, na forma de beta-caroteno, possuem função biológica funcional ativa, sendo esta essencial para manutenção, desenvolvimento e crescimento do tecido epitelial, indispensável para visão noturna e função imunológica (VERONEZI, 2007).

Entre os compostos bioativos são destaqueos ácidos graxos presentes na semente de abóbora,os quais são os mais investigados atualmente. De acordo com a literatura estão presentesácidos graxosoléico, linoléico, palmítico e também vitaminas lipossolúveis, como a vitamina E (tocoferol) (MONTESANO,2018).

Considerando a importância dos diversos efeitos benéficos da semente de abóbora para a saúde humana, o objetivo do presente estudo foi correlacionar diversos artigos já existentes sobre este vegetal e pontuar os principais nutrientes e propriedades funcionais presentes na semente de abóbora.

\section{METODOLOGIA}

Esse trabalho trata-se de uma revisão de literatura de artigos e teses, publicados entre 1996 e 2019, que abordaram assuntos relacionados à semente de 
abóbora. Para a busca, utilizou-se as bases de dados PubMed, Medline e Google Acadêmico, disponíveis na internet.

As palavras-chave empregadas na busca foram: "abóbora", "semente de abóbora", "composição", "benefícios", "patologias", "antioxidantes", "nutrição", "compostos bioativos", "nutrientes", "pumpkinseed", "health", "disease", "nutrients", "antioxidant", "benefits of pumpkin seed".

A metodologia empregada foi revisão de literatura, que se baseia na seleção e avaliação crítica de publicações consideradas relevantes, a fim de traçar um raciocínio teórico que estruture o desenvolvimento do tema selecionado.O critério de seleção inicial foi perante o título, os trabalhos que estavam relacionados com a semente da abóbora permaneceram para a próxima fase. Feito isso, foram lidos os resumos de todos os artigos para uma nova escolha, optando assim pelos que estavam relacionando a semente do vegetal com os aspectos nutricionais, e deixando de lado os que abordavam sobre cultivo.

Com a finalização dessa busca foram selecionados 21 artigos, somando-se de todas as plataformas. Porém, ao decorrer da escrita do trabalho, houve-se a necessidade de nova procura, pois se verificou quantidades escassas de certos assuntos no fichamento. Para isso, a pesquisa foi realizada através de nomes de autores que haviam sido citados nos artigos já arquivados, para verificação afundo de informações e em busca de novas, totalizando 49 artigos.

\section{COMPOSIÇÃO NUTRICIONAL}

Del-Vechio (2004) relatou que 3,32\% do peso da abóbora correspondem ao peso das sementes, as quais são conhecidas principalmente por sua composição de elevado teor proteico e lipídico. Porém, de acordo com Casaroli et al. (2006), a abóbora é uma das hortaliças que necessita de maiores estudos e testes para avaliação da qualidade fisiológica de suas sementes.

Tradicionalmente utilizada na alimentação de povos orientais e em países como a Grécia, as sementes de abóbora destacam-se pelos teores de ácidos graxos poli e monoinsaturados, vitaminas $E$ e do complexo $B$ e minerais como ferro, potássio e magnésio (MAKNI, 2008; PUMAR, 2008;TRUCOM, 2006).

Ao fazer um comparativo de 100 gramas entre a semente e a parte nobre do vegetal, perante o Banco de Dados de Composição de Alimentos do USDA e o artigo (STORCK, 2013), conforme mostra a Tabela 1.

Tabela 01. Correlação da composição físico-química da semente de abóbora e abóbora.

\begin{tabular}{llllll}
$\begin{array}{l}\text { Proteína } \\
(\mathrm{g})\end{array}$ & $\begin{array}{l}\text { Carboidrato } \\
(\mathrm{g})\end{array}$ & $\begin{array}{l}\text { Lipídeo } \\
(\mathrm{g})\end{array}$ & $\begin{array}{l}\text { Umidade } \\
(\mathrm{g})\end{array}$ & $\begin{array}{l}\text { Fibra } \\
(\mathrm{g})\end{array}$ & $\begin{array}{l}\text { Caloria } \\
(\mathrm{kcal})\end{array}$ \\
\hline 1,0 & 2,7 & 0,1 & 95,9 & 1,7 & 12 \\
1,0 & 6,5 & 0,1 & 91,6 & 0,5 & 26 \\
& & & & & \\
23,48 & 37,55 & 9,41 & 0 & 25,22 & 329,04 \\
35,71 & 14,24 & 46,43 & 0 & 10,7 & 607
\end{tabular}

United States Departamento of Agriculture; b. úmida = base úmida; b. seca = base seca. 
Storck (2013) avaliou a semente de abóbora em base úmida, portanto, foi calculada a base seca através das análises encontradas, para ser fidedigna a comparação com o Banco de Dados de Composição de Alimentos do USDA, o qual tem como padrão a base seca.

De acordo com a tabela acima, foi possível verificar a discrepância dos valores encontrados entre as fontes. Visto que a quantidade de proteína e lipídeos da semente encontra-se distantes, pode-se supor que a variável se explica devido à espécie analisada, ao tipo de plantio, colheita, qualidade e composição, afetando diretamente nos resultados, tendo em vista que uma tabela é brasileira e a outra americana.

Em contrapartida, os valores obtidos da parte nobre da abóbora tiveram menos variância em sua composição, como é o caso da proteína, lipídeos e umidade.

Devido à diferença relevante da composição encontrada nas tabelas utilizadas, serão abordados os dados encontrados por Storck (2013)para correlação entre a semente e a polpa da abóbora, com o intuito de aproximar à realidade brasileira.

Em relação à composição proteica, a semente possui maior teor quando comparado à polpa, sendo uma considerável fonte de proteína, mesmo que de baixo valor biológico.

As sementes, possuem maior teor de lipídeos, da mesma forma ocorre com a da abóbora, podendo ser verificado que a semente possui o dobro do teor da polpa.

De acordo com Sant'anna (2005), os ácidos graxos predominantes no óleo da semente de abóbora são o ácido graxo linoleico $(47,7 \%)$, o oleico $(30,0 \%)$, o palmítico $(11,54 \%)$ e o esteárico $(9,49 \%)$.

Quanto aos carboidratos, a semente também contém valores maiores se comparado à polpa, além disso, é uma excelente fonte de fibras, tornando-a um carboidrato complexo, com baixo índice glicêmico.

A utilização dos chamados subprodutos (como a semente, por exemplo) é pouco difundida, sendo por diversas vezes descartada. Porém,pode-se verificar que a composição da semente é superior em relação a todos os macronutrientes e fonte energética, se comparado à polpa, reforçando o benefício de sua utilização.

Uma porção ideal para consumo diário é de aproximadamente 40 gramas, a qual contém 2,26 gramas de proteína, 3,62 gramas de carboidrato, 0,9 gramas de lipídeos, 2,43 gramas de fibras e 31,72 kcal.

Esse valor de fibras representa cerca de 10\% da recomendação diária segundo a Referência de Ingestão Dietética (do inglês: Dietary Reference Intakes - DRI). Sabese que devido à prevalência do consumo de produtos industrializados, há dificuldade na ingestão total dessa recomendação, portanto a semente da abóbora é uma alternativa considerável para atingi-la.

\section{COMPOSTOS BIOATIVOS}

As sementes de abóboras possuem elevada quantidade de substâncias capazes de proporcionar benefícios à saúde, prevenindo ou tratando doenças e até mesmo favorecendo o funcionamento do organismo, que são intitulados compostos bioativos (VERONEZI, 2012).

Os ácidos graxos insaturados, principalmente os poliinsaturados, são um dos compostos que produzem efeitos especiais no organismo. Um dos tipos de ácidos graxos essenciais para o metabolismo é o $\omega 6($ MARTIN et al., 2006). Foi verificado por Aued-Pimentelet al., (2004) que o óleo de sementes de abóbora apresenta uma composição em torno de $40 \%$ desse ácido graxo (linoleico). 
Outro composto que possui função ativa no organismo é o tocoferol. É encontrado na forma de alfa-tocoferol, que é o mais abundante nos alimentos vegetais, sendo o com maior atividade de vitamina $\mathrm{E}$; e o gama-tocoferol, que apresenta maior atividade antioxidante (ISNARDYet al., 2003). Essa atividade atua como interruptora das reações dos radicais livres das membranas celulares, como também protege os ácidos graxos insaturados dentro das membranas e das lipoproteínas plasmáticas (TRABER, 2007).

Na semente de abóbora também há a presença de carotenoides, um pigmento natural lipossolúvel que possui atividade antioxidante, através da interaçãocom radicais livres e sequestro do oxigênio, e atividade depró-vitamina $A$ (UENOJOet al., 2007). Essa vitamina é fundamental para a visão noturna, crescimento, desenvolvimento e a manutenção do tecido epitelial, além de possuir função protetora do sistema imunológico (MELĚNDEZ-MARTíNEZ et al., 2004).

Já os compostos fenólicos, que englobam os flavonoides, os fitoestrógenos e os resveratróis, segundo Kris-Ethertonetal (2002), atuam como agentes antipatogênicos e contribuemna pigmentação (NACZK \& SHAHIDI, 2004).As sementes de abóbora são ricas em fitoestrógenos, que possuem efeitos como a redução do colesterol, prevenção de tipos de câncer e aumento da imunidade corporal (SANT'ANNA, 2005).

Em um estudo realizado por PHILLIPS et al. (2005), onde se analisaram esses compostos presentes em várias sementes consumidas nos Estados Unidos da América, foram encontrados $265 \mathrm{mg} / 100 \mathrm{~g}$ de fitoesteróis totais em sementes de abóbora. Esse resultado foi semelhante ao encontrado para as sementes de girassol e linhaça, sendo que a linhaça é a semente mais rica em fitoesteróis conhecida.

Sabe-se que o consumo frequente de compostos bioativos traz vários benefícios à saúde, é possível utilizar as sementes de abóboras na fortificação e tecnologia de alimentos, ou como fonte para a extração de óleos não convencionais, que podem ser utilizados em alimentos industrializados ou como tempero em saladas (VERONEZI, 2012).

\section{PROPRIEDADES FUNCIONAIS FISIOLÓGICAS}

As sementes de abóbora possuem fitoesteróis que estão relacionados a diversas propriedades, tais como a redução do colesterol, prevenção decertos tipos de câncer e aumento da imunidade corporal (SANT'ANNA, 2005).

É também atribuída às sementes de abóbora uma ação anti-helmíntica, devido a um composto chamado cucurbitacina, o que explica o uso das sementes de abóbora na medicina popular como vermífugo (PHILLIPS et al., 2005)

As sementes de Cucurbita $s p$ têm sido usadas por um longo tempo na medicina chinesa, com relatos de efeitos contra parasitas intestinais, tratamento de problemas de vesícula e próstata biliares. Além disso, sementes não mineradas têm efeito hipoglicêmico, atuando também como antioxidante, anticancerígena e antiinflamatória (ADAMS et al., 2012).

Neste estudo realizado por Makni (2010) com ratos Wistar, foram avaliados os efeitos antiaterogénicas e hepatoprotetores presentes da semente de abóbora e semente de linho. O trabalho foi realizado em 30 ratos machos, divididos em três grupos: um grupo controle, grupo alimentado com a dieta com $1 \%$ de colesterol e grupo com dieta enriquecida com linho e mistura de sementes de abóbora também com $1 \%$ de coleterol. No grupo de colesterol, foi registrado aumento nos níveis de lipídeos e enzimas hepáticas em $65 \%$ e $41 \%$, respectivamente, se comparado ao grupo controle. 
Já no grupo alimentado com dieta enriquecida com linho e mistura de sementes de abóbora, tanto no plasma, quanto no fígado, houve redução de $11 \%$ e $16 \%$ nos níveis de lipídeos, em comparação ao grupo do colesterol. Em conclusão, o estudo sugeriu que o linho e sementes de abóbora possuem efeito significante na atividade antiaterogênica de escala quando administrado a ratos com hipercolesterolemia.

Há cerca de duas décadas, tem-se investigado a relação entre o consumo de vitaminas e de carotenoides e a gênese do câncer. Um dos maiores interesses em relação aos carotenoides é arelaçãoda ação antioxidante que reduz o estresse oxidativo do organismo, atuando na redução de determinados tipos de câncer, de doenças cardiovasculares, bem como sobre o sistema imunológico (GOMES, 2007; LEUNG, 2008).

Ademais, fibras alimentares são definidas como polissacarídeos, oligossacarídeos, ligninas e substâncias associadas resistentes à digestão humana, encontradas em sua maioria associadas a outros polissacarídeos na parede celular de vegetais. As fibras exercem funções importantes na manutenção da saúde humana, pois são responsáveis pela atenuação dos níveis de colesterol e glicose sanguíneos, além de reduzir o risco de câncer do cólon. Sua maior ação ocorre no intestino humano, provocando laxação, ao aumentar o volume e o peso fecal, acelerando o trânsito intestinal. Além desses efeitos, a fibra alimentar também aumenta a sensação de saciedade e diminui os picos glicêmicos, o que contribui para o controle do peso (MOURA, 2009).

A farinha de semente de abóbora possui efeito laxativo, e ainda promove redução da glicemia e diminuição de triacilgliceróis e colesterol sanguíneos. Por essas razões essa farinha possui grande potencial de uso como ingrediente alimentar, em função das suas propriedades funcionais (MOURA, 2009).

De acordo com Sant'anna (2005), o ácido graxo linoleico, predominante nas sementes de abóbora, é poliinsaturado, o que o qualifica como mais benéfico em relação a outros ácidos graxos. Estudos demonstram que o consumo dietético desta gordura está associado com a redução de doenças cardiovasculares (DJOUSSE et al., 2001; RASTOGI et al., 2004). Eles podem ter efeitos benéficos á saúde e podem prevenir doenças crônicas (AL-KHALIFA, 1996; KUMAR et al., 2006).

Além de todos esses benefícios, em um estudo realizado com camundongos machos e fêmeas, foi analisado que o peso corporal dos animais tratados com dose de 1000 $\mathrm{mg} / \mathrm{kg}$ de extrato hidroalcóolico de semente de abóbora, durante um período de 30 dias, apresentaram melhora em comparação com o grupo de controle (CRUZ et al., 2006).

\section{FATORES ANTINUTRICIONAIS}

Sabe-se que a semente de abóbora possui compostos bioativos, os quais trazem inúmeros benefícios a saúde, porém, possuem também substâncias antinutricionais, que interferem na digestibilidade e absorção de nutrientes ou podem até ser tóxicas, dependendo da quantidade que são consumidas (PARRA e DUAILIBI, 2004).

Os cianetos são compostos produzidos naturalmente por reações bioquímicas e são capazes de se complexarem (em baixas concentrações) com praticamente qualquer metal pesado, sendo algumas espécies altamente tóxicas. Pode ser letal em doses médias de $50-60 \mathrm{mg} / \mathrm{kg}$, pois é um inibidor da citocromo oxidase, o que resulta no bloqueio da cadeia transportadora de elétrons durante o processo de respiração celular (WOGAN e MARLETTA, 2010). 
Akwaowoet al. (2000), quando analisaram as sementes de abóboras, verificaram que a quantidade de cianeto aumenta com o aumento da maturação. Em contrapartida, percebeu-se que quando as sementes receberam tratamentos térmicos, como cozimento e torrefação, os teores de cianetos diminuíram (DELVECHIO et al., 2005).

Outro composto é a saponina, a qual também apresenta propriedades tóxicas aos seres humanos. Sua ação lipofílica facilita a complexação com esteróides, proteínas e fosfolipídeos das membranas celulares, alterando sua permeabilidade ou causando sua destruição (FRANCISet al., 2002).

O inibidor de tripsina está presente no trato intestinal humano, diminuindo a digestibilidade proteica de sementes que foram insuficientemente cozidas, o que leva a um aumento na produção enzimática pelo pâncreas (CARDOSO et al., 2007).

Ao analisar esses estudos, é possível verificar que as sementes de abóbora são importantes fontes de compostos bioativos, embora possuam certos fatoresantinutricionais, que felizmente podem ser reduzidos ou eliminados com 0 tratamento térmico.

\section{A SEMENTE COMO SUBPRODUTO}

No Brasil, o desperdício de alimentos éalto, chegando a 26 milhões de toneladas por ano, o que poderia alimentar 35 milhões de pessoas, e cerca de $60 \%$ desseresíduourbano produzido é de origem alimentar(EMBRAPA, 2009).

Na produção de refeições, cerca de $30 \%$ dos alimentos são perdidos devido a fatores como colheita, transporte, armazenamento, preparo, exposição, entre outros. $O$ desperdício no ambiente domiciliar pode chegar a $20 \%$, devido à utilização inadequada dos alimentos (IPEA, 2009).

De acordo com Rochaet al. (2008), cascas, talos e folhas são boas fontes de fibras e lipídios, tendo-se como exemplos as sementes de abóbora. As partes não aproveitáveis dos alimentos poderiam ser utilizadas, enfatizando o enriquecimento alimentar, diminuindo o desperdício e aumentando o valor nutricional das refeições, pois esses produtos podem ser mais nutritivos do que a própria parte nobre do vegetal. (SOUZA et al., 2007).

Souza et al. (2010), em seu experimento, desenvolveu biscoitos tipo "cookie" com substituição de $30 \%$ da farinha de trigo por diferentes frações de semente de abóbora (semente de abóbora integral, semente de abóbora da fração peneirada e da fração retida na peneira), e foram avaliados quanto à sua composição química, coloração, parâmetros físicos e aceitação sensorial. Os biscoitos formulados com semente de abóbora da fração retida apresentaram alto índice de aceitação $(71,11 \%)$, concluindo-se que, em geral, produtos com adição de farinhas de cascas e sementes de vegetais em níveis de até $25 \%$, com intuito de aumentar o teor de fibras, ainda resultam em bom índice de aceitação.

Além do melhoramento da composição nutricional das refeições, o uso de partes não convencionais dos vegetais, como folhas, talos, cascas e sementes são uma ótima alternativa para redução do desperdício e do lixo domiciliar e uma possibilidade de economia.

\section{CONSIDERAÇÕES FINAIS}

Tratando-se da abóbora, há bastante literatura disponível, porém observou-se que existe pouca literatura acerca da semente, principalmente quando se trata de 
compostos bioativos e de seus benefícios. Para tanto, sugere-se mais estudos e análises específicas e detalhadas que quantifiquem os compostos presentes na semente, sua biodisponibilidade, além da quantidade ideal a ser ingerida para obter tais efeitos no organismo.

Ademais, a semente de abóbora é rica em ácidos graxos poliinsaturados, podendo ser uma ótima fonte para o consumo dietético e para composição de suplementos. Mas para isso, também há necessidade de mais estudos sobre a extração adequada, conservação, bem como sua ideal utilização, visto que ainda são muito descartados, mesmo tendo efeitos essenciais para saúde.

\section{REFERÊNCIAS}

ADAMS, G. G. Extraction, isolation and characterisation of oil bodies from pumpkin seedsfor therapeutic use. Elsevier Ltda. 2012.

AL-KHALIFA, A. S. Physicochemical characteristics, fatty acid composition, and lipoxygenase activity of crude pumpkin and melon seed oils. Journal of Agricultural and Food Chemistry. v. 44. p.964-966, 1996. https://doi.org/10.1021/jf950519s

AUED-PIMENTEL, S.A. et al. Composição de ácidos graxos e tocoferóis em óleos especiais. In: Congresso Brasileiro de Ciência e Tecnologia de Alimentos. Recife. Anais, 2004.

AKWAOWO, E.U. et al Mineralsandantinutrients in Flutedpumpkin (TelfairiaoccidentalisHook f.). FoodChemistry. London.v.70, n.1, p.235- 240, 2000

BOSCHI, K. Caracterização das propriedades químicas e antioxidantes da semente, germinados, flores, polpa e folha desenvolvida de abóbora (Cucurbita pepo L.), 2015.

CARDOZO, K.H.M. et al. Metabolites from algae with economical impact.Comparative Biochemistry andPhysiology, v.146, p.60-78, 2007.

CASAROLI, D. et al. O teste de frio sem solo em sementes de abóbora. Ciência Rural, Santa Maria, v.6, n.36, p.1923-1926, 2006.

CHEN, L. Antioxidant activities of sulfated pumpkin polysaccharides.International $\begin{array}{llll}\text { Journal of } & \text { Biological } & \text { Macromolecules. }\end{array}$ https://doi.org/10.1016/j.ijbiomac.2018.12.261

CHEN, L.; HUANG, G. Antioxidant activities of phosphorylated pumpkin polysaccharide. International Journal of Biological Macromolecules, v. 125, p. 256-261, 2019. DOI: 10.1007/s10811-006-9121-z

CARVALHO, M. L. M. et al. Teste de raios $x$ na avaliação da qualidade de Sementes de abóbora. Revista Brasileira de Sementes. v. 3. n. 2. p.221-227, 2009. http://dx.doi.org/10.1590/S0101-31222009000200026. 
CRUZ, R. C. B. et al. Toxicity evaluation of Cucurbita maxima seed extract in mice. Pharmaceutical Biology. v. 44, n. 4, p. 301-303, 2006.

https://doi.org/10.1080/13880200600715886

DEL-VECHIO, G. et al. Efeito do tratamento térmico em sementes de abóboras (Curcubita spp.) sobre os níveis de fatores antinutricionais e/ou tóxicos. Ciência e Agrotecnologia. Lavras, v.2 9, n. 2, p. 369-376, 2005. http://dx.doi.org/10.1590/S1413-70542005000200014

DJOUSSE. L., et al. Relation between dietary linolenic acid and coronary artery disease in the national heart, lung, and blood institute family heart study. American Journal of Clinical Nutrition. v. 74, p. 612 619, 2001. DOI: 10.1093/ajcn/74.5.612

EMBRAPA (EMPRESA BRASILEIRA DE PESUISA AGROPECUÁRIA). O papel dos bancos de alimentos na redução do desperdício de alimentos. Set, 2007. Disponível em: http://pessoal.utfpr.edu.br/marlenesoares/arquivos/BancodeAlimentosEmbrapa.pdfro berto_machado_-_19.09.pdf/view. Acesso em: 09 Abr. 2019.

FRANCIS, G. et al. The biologicalactionofsaponins in animal systems: a review. British Journal of Nutrition. Cambridge. v.88, n.6, p.587-605, 2002. DOI:10.1079/BJN2002725

GOMES, F.S. Carotenoides: uma possível proteção contra o desenvolvimento de câncer. Revista de Nutrição, v.20, p.537- 548, 2007. http://dx.doi.org/10.1590/S1415-52732007000500009

IPEA (INSTITUTO DE PESQUISA ECONÔMICA APLICADA). Desperdício - Custo para todos - Alimentos apodrecem enquanto milhões de pessoas passam fome. Ano 6. Edição 54. Out, 2009. Disponível em: http://www.ipea.gov.br/desafios/index.php?option=com content\&id=1256. Acesso em: 09 Abr. 2019.

ISNARDY, B. et al. Effects of a-, c-, and d-tocopherols on the autoxidation of purified rapeseed oil triacylglycerols in a system contain in glow oxygen. Journal of Agricultural and Food Chemistry. Easton. v.51, n.26, p.7775- 7780, 2003. doi: 10.1016/j.nbt.2011.04.013.

KUMAR, S.A., SUDHAHAR, V., VARALAKSHMI, P. Protective role of eicosapentaenoate-lipoate (EPA-LA) derivative in combating oxidative hepatocellular injury in hypercholesterolemic atherogenesis. Atherosclerosis. v. 189, p. 115-122, 2006. DOI: 10.1016/j.atherosclerosis.2005.11.037

KRIS-ETHERTON, P., et al. Bioactive compounds in foods: their role in the prevention of cardiovascular disease and cancer. American Journal of Medicine. v. 113, p. $71 \mathrm{~S}$ 88S, 2002. DOI:10.1016/s0002-9343(01)00995-0 
LEUNG, I.; PHIL, M. Macular pigment: new clinical methods of detection and the role of carotenoids in age-related macular degeneration. Optometry, v.79, p.266-272, 2008.

LI, Q.H.; TIAN, Z.; CAI, T. Y. Estudo sobre a ação hipoglicêmica de extrato de abóbora no rato diabético. Acta Nutrimenta Sinica. v.25, p. 34 - 36, 2001.

MAKNI, M. et al. Hypolipidemic and hepato protective effects of flax and pumpkin seed mixture rich in $\omega-3$ and $\omega-6$ fatty acids in hypercholesterolemic rats. Food Chemical Toxicology, v. 46, n. 12, p. 3714- 3720, 2008. doi: 10.1016/j.fct.2008.09.057.

MARTIN, P.C. Abóboras. Nutrição em Pauta. n.56, 2002. Disponível em: $<$ http://www.nutricaoempauta.com.br/ lista_artigo.php?cod=195>. Acesso em: 13 maio, 2008.

MELÉNDEZ-MARTÍNEZ, A.J. et al. Importancia nutricional de los pigmentos carotenoides. Archivos Latinoamericanos de Nutrición. Caracas. v.54, n.2, p.149154, 2004.

MONTESANO, D. Chemical and Nutritional Characterization of Seed Oil from Cucurbita maxima L. (var. Berrettina) Pumpkin Foods. v. 7, p. 1-14, 2018. doi: $10.3390 /$ foods 7030030

MOURA, F. A. et al. Cookie elaborated with different fractions of pumpkin seed (Curcubita maxima). Alimentos e Nutrição. Araraquara, v. 21, n. 4, p.579-585, out./dez. 2010.

NACZK M.; SHAHIDI F. Extraction and analysis of phenolics in food. Journal Chromatographic A. Amsterdam. v.1054, n.1-2, p.95-111, 2004. https://doi.org/10.1016/j.chroma.2004.08.059

PARIS, S.H. Abobrinha: história, diversidade e distribuição. Hortaliças e Tecnologia. v. 6, p. $6-13,1996$.

PARIS, S. H. et al, Avaliação das relações genéticas em Cucurbita pepo (Cucurbitaceae) utilizando marcadores de DNA. Theoretical and Applied Genetics. p. 971-978, 2003.

PARRA, R.G.C.; DUAILIBI, S.R. Uso de alimentos funcionais: os principais e as quantidades necessárias para se obter o apelo de saudabilidade. Alimentos do milênio: importância dos transgênicos, funcionais e fitoterápicos para a saúde. São Paulo. Editora: Signus, cap. 1, p.1-14, 2004.

PHILLIPS, F. Vegetarian nutrition. British Nutrition Foundation. v. 30. p. 132-167, 2005.

PUMAR, M. et al. Avaliação do efeito fisiológico da farinha de semente de abóbora (Cucurbita maxima, L.) no trato intestinal de ratos. Ciência e Tecnologia de Alimentos. Campinas. v. 28, P. 7-1 3, 2008. http://dx.doi.org/10.1590/S010120612008000500002 
RASTOGI, T., et al. Diet and risk of ischemic heart disease in India. American Journal of Clinical Nutrition. v. 79, p. 582-592, 2004. DOI:10.1093/ajcn/79.4.582

ROCHA, S. A. et al. Fibras e lipídios em alimentos vegetais oriundos do cultivo orgânico e convencional. Revista Simbio-Logias, v. 1, n. 2, p. 1-9, 2008.

SAAVEDRA, M. J. et al. Evaluation of the potential of squash pumpkin by-products (seeds and shell) as sources of antioxidant and bioactive compounds. Journal of Food Science and Technology, v. 52, n. 2, p. 1008-1015, 2013. doi: 10.1007/s13197-013-1089-5

SANT'ANNA, L. C. Avaliação da composição química da semente de abóbora (Cucurbita pepo) e do efeito do seu consumo sobre o dano oxidativo hepático de ratos (Rattusnovergicus). Florianópolis, 2005. Dissertação (Mestre em Nutrição).

SILVA, M. C. P. Teste de tetrazólio em sementes de abóbora \{Cucúrbita moschata). (Monografíalato senso)- UFLA, Lavras, 2006.

SOUZA, P. D. J. et al. Análise sensorial e nutricional de torta salgada elaborada através do aproveitamento alternativo de talos e cascas de hortaliças. Alimentos e Nutrição. Araraquara. v.18, n.1, p.55-60, 2007.

SOUZA, C. O. et al. Carotenoides totais e vitamina A de cucurbitáceas do Banco Ativo de Germoplasma da Embrapa Semiárido. Ciência Rural, v. 42, n. 5, p. 926-933, 2012. http://dx.doi.org/10.1590/S0103-84782012005000024.

STORCK, C. R. et al. Folhas, talos, cascas e sementes de vegetais: composição nutricional, aproveitamento na alimentação e análise sensorial de preparações. Ciência Rural, v. 43, n. 3, p. 537-543, 2013. http://dx.doi.org/10.1590/S010384782013000300027.

TADMOR Y, P. S.H, MEIR A, SCHAFFER A. A, LEWINSOHN E. O papel de duplo o gene da pigmentação $B$, em que o teor de carotenóides e vitamina $E$ em polpa (Cucurbita pepo) mesocarpo. Journal Agricultural Food Chemistry. v. 53. 2005.

TRUCOM, C. A importância da linhaça na saúde. São Paulo. ed. 1.p.144, 2006.

TRABER, M.G. et al. Handbook of Vitamins. Boca Raton: CRC Press, 2007. cap. 4, p.153-174.

UENOJO, M. et al. Carotenoides: propriedades, aplicações e biotransformação para formação de Compostos de aroma. Química Nova, v.30, p.616-622, 2007. http://dx.doi.org/10.1590/S0100-40422007000300022

USDA. National Nutrient Database for Standard Reference, 2018. 
VERONEZI, C. M. Utilization of Pumpkin (Cucurbita sp) Seeds as a Food Source. Revista Brasileira de Produtos Agroindustriais, v.14, n. 1, p. 113-124, 2012.

WOGAN, G.N.; MARLETTA, M.A. Componentes perjudiciales o potencialmente perjudiciales de los alimentos. Química de los alimentos. Zaragoza: Acribia, cap. 12, p.775-811, 2010.

ZHANG Y, Y. H. Estudo sobre efeito de hipoglicemia. Food Research Internatinal. v.42. p.641-646. 2002. 